Vol. 5 (1996): 487-490.

\author{
Foreword
}

\title{
Embryo transfer technology and its use in enhancing dairy cattle breeding
}

Asko Mäki-Tanila and Esa A. Mäntysaari

Agricultural Research Centre of Finland, Institute of Animal Production, FIN-31600 Jokioinen, Finland, e-mail: asko.maki-tanila@mtt.fi

\section{Introduction}

The rate of genetic progress in a breeding programme is determined by accuracy of genetic evaluation, selection intensity, amount of genetic variation in the trait under selection and the length of generation interval. Two of these, selection intensity and generation interval, are largely dependent on the type of breeding programme and the selection scheme in use; of which several different modifications can exist in populations of domestic animals. The selection differential is determined by the proportion of individuals selected from the group of potential parents and is therefore influenced by the reproductive capacity of the species. For uniparous animals such as cattle or horses, the male is capable of producing hundreds of offspring in a lifetime while the female seldom produces more than 3 to 8 . Therefore the majority of female young have to be raised as replacements. In modern animal breeding the reproductive rate of males has been maximised via the use of artifi- cial insemination (AI). It has been estimated that the Dutch bull Sunny Boy (born 1985) has produced already more than a million offspring around the world (van Velzen 1996)! Since the number of offspring for a modern AI-bull seems almost infinite, it would appear that the reproductive rate of females is a limiting factor in an effective cattle breeding programme.

The use of embryo transfer (ET) to improve the rate of female reproduction is not a recent innovation. The first successful ET using rabbit embryos were done as early as 1890 (refer to Gordon 1994). In cattle, development of ET technology started in the 1940's but did not become popular until the non-surgical techniques to recover embryos from donors and to transfer them into recipients became available in the mid1970 's. These routines paved the way for the commercial exploitation of cattle ET in North America and subsequently also in western Europe. The reports of International Embryo Transfer Society show that in 1995 more than 400000 cattle embryos were transferred worldwide (IETS 1996). 


\section{AGRICULTURAL AND FOOD SCIENCE IN FINLAND}

\section{Embryo transfer}

Routine technique of ET involves treating the donor cow with follicle stimulating hormone (FSH) or pregnant mare serum gonadotrophin (PMSG) hormones (see Hasler 1992). Typically these lead into a superovulation response averaging 5 embryos per cow per treatment. The superovulation programme can be repeated up to five times a year to potentially yield 25 transferrable embryos per year per donor cow (Kruip 1994). Parallel to superovulation treatment the recipient cows are synchronised into the same stage of the oestrus cycle as the donor cow. On average, pregnancy rates of $40 \%$ to $60 \%$ have been achieved from transfers, with the success depending on whether frozen or fresh embryos have been used. Compiling the figures we can approximate that the MOET (multiple ovulation and embryo transfer) operation could yield an average of 10-15 conceptions or 5 to 7 female calves per selected donor per year. The efficiency has remained at this level over the last few years suggesting that no large improvements are to be expected in MOET based methods (Hasler 1992). Technologies to increase the amount of transferrable embryos, such as embryo splitting or nuclear transfer have been introduced, as well as embryo sexing to avoid transferring the embryos of unwanted sex.

\section{ET breeding schemes}

The impact of MOET technology on selection has been thoroughly investigated in animal breeding research. The influence on the genetic improvement of beef cattle was studied by Land and Hill (1975). However, as Nicholas and Smith (1983) recognized, the major potential of ET was in improvement of dairy cattle, although its use in traditional progeny testing schemes has been found to contribute very little to the rate of genetic progress in national breeding programmes (e.g. McDaniel and Cassell 1981). Nicholas and Smith (1983) predicted that considerable gains can be made by relying on quickly available information from full and half sister groups produced by ET, rather than waiting for more accurate progeny testing of bulls. Cost savings can also be made by restricting the breeding operations to a small nucleus herd of elite cows. Juga and Mäki-Tanila (1987) showed by computer simulation that, the analytical predictions were slightly too optimistic. Much simulation and theoretical work has since been carried out on MOET schemes, with special attention being paid to the risk of inbreeding within nucleus. Woolliams (1989) has shown that mating design in which eggs from one cow are fertilised with semen from several bulls substantially reduces the rate of inbreeding for the same level of genetic progress.

Several MOET breeding schemes or herds have been established, such as Genus in the UK and Delta in the Netherlands for Holstein cattle. An open dispersed MOET scheme was set up for Finnish Ayrshires in 1990 (Mäntysaari et al. 1996).

\section{Research on embryo technology at Jokioinen}

There has been active research on embryo technology at the Agricultural Research Centre of Finland (Jokioinen) since the early 1980s. Initially, the main research interest was to support the development of practical work on farms, therefore topics such as freezing and superovulation method received most attention. The research team led by Peter Bredbacka has been working in close co-operation with the other groups in the animal breeding section which has influenced the choice of research topics. The strategic target has been to develop a methodology to maximise the number of desired progeny from limited available resources. Encouraging results were obtained concerning the timing of 
Vol. 5 (1996): 487-490.

superovulatory hormone treatment with respect to follicle development (Huhtinen et al. 1992). It became apparent that research should focus on questions of in vitro techniques for embryo production, including oocyte maturation, in vitro fertilisation and in vitro culturing of embryos, due to the limited yields of in vivo embryo production. Substantial advances have been made in mammalian preimplantation embryo culturing in recent years. This journal issue contains results on the complexity of actions and interactions between different compounds in culture medium (Bredbacka and Bredbacka $1996 a, b)$ and a presentation of time-lapse video monitoring of embryonic growth (Peippo and Bredbacka 1996a). In a cost effective in vitro embryo production the quality control of embryos transferred is crucial. In judging fresh embryos an approach where the embryonic cells were stainded by DAPI has been tested in a horse ET trial (Huhtinen and Bredbacka 1996).

The cost of an ET breeding scheme can be considerably reduced if embryos are sex-sorted before transfer. Sexing is based on a PCR (polymerase chain reaction) method to selectively amplify Y chromosome specific DNA regions (e.g. Bredbacka and Peippo 1991). Simplified methods guarantee performing the sexing with- in a reasonable time to maintain conception rate still high (Bredbacka et al. 1995). The major step in this and other analyses of preimplantation embryos is the requirement for a small biopsy. Embryo biopsy (e.g. Bredbacka et al. 1994, Bredbacka 1996) and related bisection methods (e.g. Bredbacka et al. 1996) have been a subject of active research in recent years. Alternatively, the sample can be taken after the embryo implantation from the foetal DNA in amniotic fluid (Peippo and Bredbacka 1996b).

Currently, the research on embryo technology is concentrating on culture and manipulation methods to support the development of embryo production with the ovum pick-up (OPU; see Kruip 1994) technique. In OPU method the oocytes are collected transvaginally from tertiary ovarian follicles in live animals using ultrasound guided punctuation. The collection is done weekly or twice a week, and can be repeated at least over a period of five months (Kruip 1994). With the technique it is possible to meet the requirements in the number of embryos per donor set by successful running of an ET breeding programme. There are plans in Finland to change the ET breeding scheme from dispersed to more centralised operation.

\section{References}

Bredbacka, K. \& Bredbacka, P. 1996a. Effect of glycine and alanine supplementation on development of cattle embryos cultured in CR1aa medium with or without cumulus cells. Agricultural and Food Science in Finland 5: 503-508,

- , \& Bredbacka, P. 1996b. In vitro production of cattle blastocysts in chemically defined medium with or without insulin supplementation. Agricultural and Food Science in Finland 5: 509-514.

Bredbacka, P. 1996. A mouse model for improving cell survival of bisected cattle embryos. Agricultural and Food Science in Finland 5: 529-534.

- , Bredbacka, K. \& Peippo, J. 1991. Experiences of using PCR for sexing bovine embryos. Reproduction in Domestic Animals 26: 75-77.

-, Jaakma, Ü. \& Müürsepp, I. 1996. Production of calves following nonsurgical transfer of fresh and refrigerated bovine demi-embryos. Agricultural and Food Science in Finland 5: 521-527.

- , Kankaanpää, A. \& Peippo, J. 1995. PCR-sexing of bovine embryos: a simplified protocol. Theriogenology 44, 2:167-176.

-, Velmala, R., Peippo, J. \& Bredbacka K. 1994. Survival of biopsied and sexed bovine demi-embryos. Theriogenology 41: 1023-1031.

Gordon, I. 1994. Laboratory Production of Cattle Embryos. CAB International, Wallingford. $640 \mathrm{p}$.

Hasler, J.F. 1992. Current status and potential of embryo transfer and reproductive technology in dairy cattle. Journal of Dairy Science 75: 2857-2879.

Huhtinen, M. \& Bredbacka, P. 1996. Non-surgical transfer of 4',6'-diamidino-2-phenylindole-stained equine embryos. Agricultural and Food Science in Finland 5: 535540. 


\section{AGRICULTURAL AND FOOD SCIENCE IN FINLAND}

- , Rainio, V., Aalto, J., Bredbacka, P. \& Mäki-Tanila, A. 1992. Increased ovarian responses in the absence of a dominant follicle in superovulated cows. Theriogenology 37,2 : 457-463.

IETS. 1996. International embryo transfer newsletter, vol $14,4: 27-30$.

Juga, J. \& Mäki-Tanila, A. 1987. Genetic change in a nucleus breeding dairy herd using embryo transfer. Acta Agriculturae Scandinavica 37: 511-519.

Kruip, T. M. 1994. Oocyte retrieval and embryo production in vitro for cattle breeding. Proceedings of the 5th World Congress on Genetics Applied to Livestock Production, 7.-12.8.1994, Guelph, Canada, vol. 20: 172-179. Land, R.B. \& Hill, W.G. 1975. The possible use of superovulation and embryo transfer in cattle to increase response to selection. Animal Production 21: 1-12.

McDaniel, B.T. \& CasselI, B.G. 1981. Effects of embryo transfer on genetic change in dairy cattle. Journal of Dairy Science. 64: 2484-2492.

Mäntysaari, E.A., Thuneberg-Selonen, T., Hyppänen,
K. \& Juga, J. 1996. Finnish embryo transfer breeding program "ASMO": Description of the goals and a summary of the results of initial selection. Agricultural and Food Science in Finland 5: 491-501.

Nicholas, F.W. \& Smith, C. 1983. Increased rates of genetic change in dairy cattle by embryo transfer and splitting. Animal Production 36: 341-353.

Peippo, J. \& Bredbacka, P. 1996a. A simple culture system for time-lapse video recording of bovine embryos. Agricultural and Food Science in Finland 5: 515-520.

- \& Bredbacka, P. 1996b. Detection of bovine foetal DNA from amniotic fluid using the polymerase chain reaction. Agricultural and Food Science in Finland 5: 541-546. van Velzen, C. 1996. The Living Legend. Veepro Holland 25: 12-15.

Woolliams, J.A. 1989. Modifications to MOET nucleus breeding schemes to improve rates of genetic progress and decrease rates of inbreeding in dairy cattle. Animal Production 49: 1-14. 